\title{
Hypopharyngeal Cancer: Epidemiological, Clinical and Paraclinical Aspects at the University Hospital Center (CHU) Gabriel Toure in Bamako
}

\author{
K. Doumbia-Singare*, F. I. Kone, M. Doumbia, B. Guindo, S. Soumaoro, N. Cisse, N. F. Konate, \\ K. Diarra, M. Sangare, S.-K. Timbo, M. Keita, A. G. Mohamed
}

Department of the CHU Gabriel Toure in Bamako, Bamako, Mali

Email: *kadidia22000@yahoo.fr

How to cite this paper: Doumbia-Singare, K., Kone, F.I., Doumbia, M., Guindo, B., Soumaoro, S., Cisse, N., Konate, N.F., Diarra, K., Sangare, M., Timbo, S.-K., Keita, M. and Mohamed, A.G. (2020) Hypopharyngeal Cancer: Epidemiological, Clinical and Paraclinical Aspects at the University Hospital Center (CHU) Gabriel Toure in Bamako. International Journal of Otolaryngology and Head \& Neck Surgery, 9, 46-51.

https://doi.org/10.4236/ijohns.2020.91007

Received: November 24, 2019

Accepted: January 16, 2020

Published: January 19, 2020

Copyright $\odot 2020$ by author(s) and Scientific Research Publishing Inc. This work is licensed under the Creative Commons Attribution International License (CC BY 4.0).

http://creativecommons.org/licenses/by/4.0/

(c) (i) Open Access

\begin{abstract}
Introduction: Hypopharyngeal cancers are ubiquitous cancers. These are very lymphophilic cancers; cervical lymph node metastases are present in $60 \%$ to $80 \%$ of patients at the time of diagnosis. Alcohol and tobacco have been implicated in their genesis. Objective: To study the epidemiological, clinical and paraclinical aspects of hypopharyngeal cancer in the ENT department of the CHU Gabriel Toure. Patients and Methods: It is a retrospective and prospective quantitative study covering a period of 4 years from June 2014 to July 2018; all patients who presented with hypopharyngeal cancer were included. Results: Thirty-five (35) patients were collected during the study period. The mean age of the patients was $44 \pm 14$ years with extremes of 16 and 78 years. The sex ratio was 0.47 . Dysphagia was the reason for consultation at $100 \%$. The average consultation time was 14 months, with extremes of 3 to 26 months. Smoking intoxication was found in 13 patients. The piriform sinus was interested in 52\%. More than half of the patients were received at the advanced stage (T3 - T4). The histology was dominated by the well-differentiated epidermal carcinoma (91\%). Conclusion: Hypopharyngeal cancer is common and occurs at all ages. T3 - T4 tumors are bad factors, hence early diagnosis and appropriate management are important for improving the prognosis.
\end{abstract}

\section{Keywords}

Cancer, Hypopharynx, Imaging, Endoscopy, Histology

\section{Introduction}

Hypopharyngeal cancers are neoformations made of anarchic and uncontrolled 
cellular proliferation, primitive or secondary, developed at the expense of the constituent tissues of the hypopharynx [1].

They represent $8 \%$ to $10 \%$ of all cancers of the upper aerodigestive tract (VADS). Its annual incidence is estimated at 1/100,000 inhabitants in Western countries [2]. In 2017, according to the report of the Mali cancer registry, hypopharyngeal cancer represented $1 \%$ of all cancers of the upper aerodigestive tract (VADS) with an incidence of 0.1 per 100,000 inhabitants [3]. These are very lymphophilic cancers; cervical lymph node metastases are present in $60 \%$ to $80 \%$ of patients at the time of diagnosis. They have significant visceral metastatic potential [4]. Alcohol and tobacco have been implicated in the genesis of these cancers [4] [5] [6].

The diagnosis is facilitated by clinical examination and imaging confirmed by histological examination of the operating room. Squamous cell carcinoma is the most frequent histological type 80\% [6] [7].

Despite improvements in radiotherapy techniques and the advent of chemotherapy, hypopharyngeal cancers have the poorest prognosis among head and neck cancers.

Hypopharyngeal cancer is one of the causes of mortality and morbidity in our country. It is with this in mind that we undertook this study in order to present the epidemiological, clinical and paraclinical profile of hypopharyngeal cancer.

\section{Patients and Methods}

It is a retrospective and prospective descriptive study having as a study the ENT department and cervico-facial surgery of the Gabriel Toure University Hospital Center (CHU) Gabriel Toure of Bamako, Mali.

It was conducted over a 4-year period from June 2014 to July 2018. We included in this study all the files of patients admitted for hypopharyngeal cancer. We did not include incomplete records, lost patients and hypopharyngeal cancers associated with other cancers of the upper aerodigestive tract. We have identified for each file the frequency, sex, age, the way of life (alcohol and tobacco poisoning), the consultation period, the signs, the site of the lesion.

Anemia: hemoglobin level less than $11 \mathrm{~g} / \mathrm{dl}$, pharyngolaryngeal CT, Abdominal ultrasound, gross appearance of the lesion, panendoscopy, histology, TNM classification, palliative treatment received.

The data were entered and checked using Epi Info 3.22 software and analyzed using software version R 3.1.2. The chi2 or Fischer tests were used.

\section{Results}

We collected 35 cases during the study period. The mean age of the patients was $44 \pm 14$ years with extremes of 16 and 78 years. The age group of [51 to 60] years was the most affected $31 \%$ or 11 cases.

The sex ratio was 0.47 . Smoking intoxication was found in 13 patients (37\%) and the link was not statistically significant $(p=0.2)$. It has been associated with 
alcoholic impregnation in 3 patients. The average consultation time was 14 months, with extremes of 3 to 26 months.

Regarding the signs: Dysphagia was found in all patients (100\%) (Figure 1) and cervical lymphadenopathy was found in 21 patients at the time of the examination.

Anemia was associated with the lesion in 7 cases (20\%) and the link was not significant $(\mathrm{p}=0.93)$.

The lesion was located in the piriform sinus in 52\% (18 cases), the posterior wall 5 cases and in all of the hypopharyngeal regions 12 cases.

Macroscopically, the lesion was budding in 25 cases (71\%), ulcerative-budding in 10 cases $(29 \%)$.

All patients underwent cervical CT and panendoscopy. The extension assessment, in particular the chest X-ray and abdominal ultrasound was performed in all patients and returned to normal.

Histologically, it was a differentiated epidermal carcinoma in 32 cases (91\%) and moderately differentiated in 3 cases (9\%).

More than half of the patients (54\%) were received at the T3N2M0 stage.

Table 1 summarizes the TNM classification according to the International Union against Cancer 2003 (UICC).

Regarding palliative treatment (Table 2), tracheotomy associated with gastrostomy was performed in more than half of the patients (57\%).

For radical treatment: Surgery associated with radiotherapy was performed in 2 patients, exclusive radiotherapy in 10 patients, chemotherapy in 10 patients. After the last two treatments, we had an evolutionary continuation in 26 patients (74\%).

We have registered 5 patients who are lost to follow-up after diagnosis. We noted 28 cases of death $(80 \%)$. The prognosis was poor with poor survival $(5 \%)$ in 4 years.

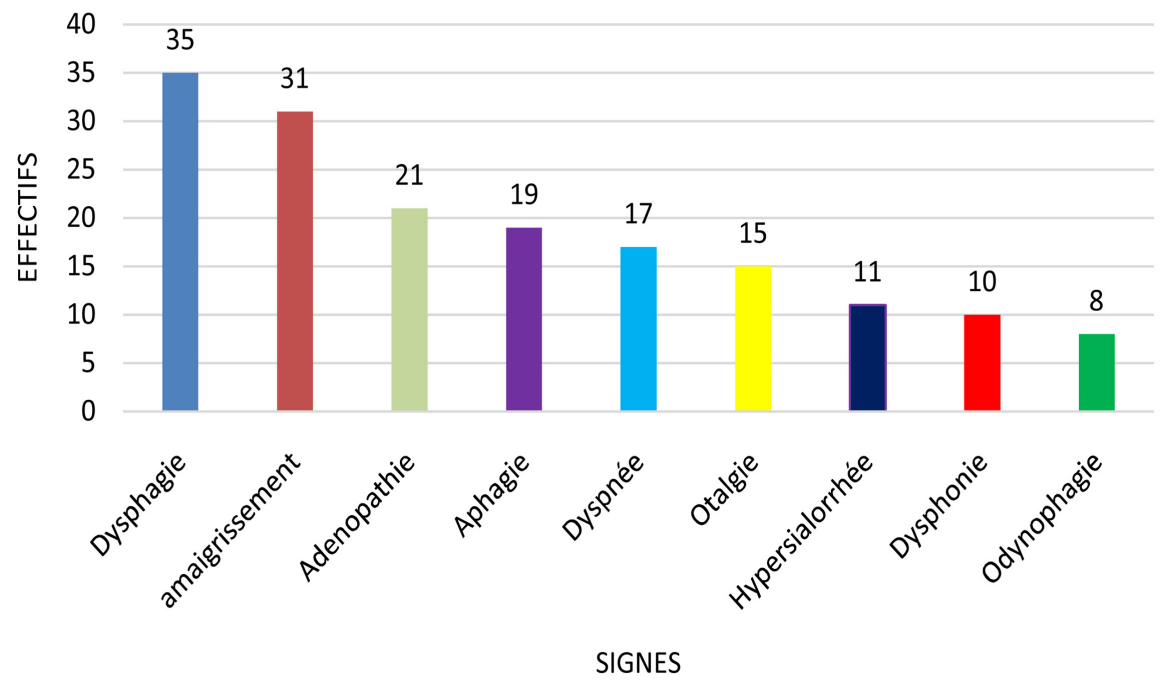

Figure 1. Distribution of patients according to signs. 
Table 1. TNM classification according to the International Union Against Cancer (UICC).

\begin{tabular}{ccc}
\hline TNM & Relative frequencies & Absolute frequencies (\%) \\
\hline T3N2M0 & 19 & 54.28 \\
T2N1M0 & 10 & 28.57 \\
T4N2M0 & 6 & 17.15 \\
Total & 35 & \\
\hline
\end{tabular}

Table 2. Distribution of patients according to palliative treatment.

\begin{tabular}{ccc}
\hline Palliative treatment received & Relative frequencies & Absolute frequencies (\%) \\
\hline Gastrectomy & 8 & 23 \\
Tracheotomy & 7 & 20 \\
Gastrectomy + Tracheotomy & 20 & 57 \\
\hline
\end{tabular}

\section{Discussion}

We have collected 35 cases of hypopharynx cancer over a period of 4 years and it represented $1.91 \%$ of ENT hospitalizations, an annual frequency of approximately 8.8 cases.

This result is close to that of TANON et al., who found 1.8 cases to 2.5 cases of the annual hospital incidence [7].

In France, LAPORTE-LEDOU B et al. in 2015 found a number of new annual cases of 5200 cases; this could be explained by the hypopharyngeal cancers that are more frequent in industrial environment, but the tobacco and the alcohol are obvious favoring factors [8].

We noted a female predominance of $66 \%$ with a sex ratio of 0.47 . The same observation was made by N'Diaye et al. who reported a female predominance of $57.6 \%$ [8]. In contrast, Tanon et al. reported a male predominance with a sex ratio of 2.2 [7]. Our series is special compared to the age of onset; the youngest of the patients was 10 years old. We share the same observation with the series by N'Diaye [9].

Classically, according to the data in the literature, the incidence of hypopharyngeal cancer is significantly higher in men compared to women for the locations of the piriform sinuses and the posterior pharyngeal wall; but it is relatively higher in women for locations in the retro-crico-arytenoid region in Anglo-Saxon and Scandinavian countries [10]. Thus in the present study in relation to localizations, among the 18 cases of localization at the level of the piriform sinus, 12 cases were women.

Tobacco and alcohol remain the main contributors [5] [6]. We noted 13 cases or $37 \%$ and the link was not statistically significant $(\mathrm{p}=0.2)$. Some authors such as N'Diaye and Tanon respectively reported $19 \%$ and $8.33 \%$ of tobacco intoxication [7] [9]. The absence of smoking intoxication in 22 of our patients suggests the role of other contributing factors that we could not identify in the present study. Sideropenic anemia was also associated with these hypopharyngeal cancers, especially in Anglo-Saxon and Scandinavian countries [11]. We noted 7 
cases and the link was not significant $(\mathrm{p}=0.93)$. The same observation was made by N'Diaye who reported $30 \%$ of sideropenic anemia in $68 \%$ of women with hypopharyngeal cancer [9].

Clinically, dysphagia was found in all patients, ie $100 \%$; however, it represents a sign of constant appeal in all patients [9] [12].

Cervical lymphadenopathy was found on clinical examination in $60 \%$ or 21 cases. This figure corroborates with the literature, carcinomas of the hypopharynx appear to have the highest lymphophilia among cancers of the head and neck [3] [7] [9].

The average consultation time was long 14 months. This could be explained by the trivialization of certain symptoms, the use of traditional healers with the corollary frequency of advanced stage (54\% at stage T3N2M0). These advanced stages at the time of diagnosis were causes of palliative treatment, in particular gastrostomy and tracheotomy.

The histological type was dominated in our study, as in the literature by squamous cell carcinoma [2] [7] [8] [9].

The prognosis was poor with a poor survival rate at 4 years. A similar observation has been made by certain authors. Poor local control remains a major cause of death in these patients [7] [9] [13].

\section{Limits of the Study}

The main limitation was the retrospective study. The sample size was small. The follow-up time was short 4 years and many of them were lost.

We noted a financial and geographic inaccessibility of radiotherapy and chemotherapy which can explain the high rate of death.

The Mali Hospital located in the center of the country is the only hospital equipped with the radiotherapy device.

\section{Conclusion}

Hypopharyngeal cancers are common and occur at all ages. The delay in consultation is an element of poor prognosis, hence informing the general population about the warning signs with a view to early consultation is important. The role of risk factors, in particular alcohol and tobacco, is difficult to determine from this study because the majority of patients did not use alcohol or tobacco.

\section{Conflicts of Interest}

The authors declare no conflicts of interest regarding the publication of this paper.

\section{References}

[1] P. Tran Ba Huy (2002) Colletions université francophone ORL, Cancer de l'hypopharynx. Ellipses, Paris, MARKETING, 204-208.

[2] Yamamoto, K., Takano, K., Kondo, A., Kurose, M., Obata, K. and Himi, T. (2018) 
Clinical and Prognostic Analysis of Hypopharyngeal Squamous Cell Carcinoma with Synchronous and Metachronous Multiple Malignancies. International Journal Experimental and Clinical Pathophysiology and Drug Research, 32, 165-170. https://doi.org/10.21873/invivo.11220

[3] Service d'anatomie et cytologie pathologique, registre des cancers du Mali (2017) Rapport 2017 des registres des cancers du Mali.

[4] Joo, Y.-H., Sun, D.-I., Cho, K.-J., Cho, J.-H. and Kim, M.-S. (2010) The Impact of Paratracheal Lymph Node Metastasis in Squamous Cell Carcinoma of the Hypopharynx. European Archives of Oto-Rhino-Laryngology, 267, 945-950. https://doi.org/10.1007/s00405-009-1166-6

[5] Blot, W.J., Mclaughlin, J.K., Winn, D.M., et al. (1988) Smoking and Drinking in Relation to Oral and Pharyngeal Cancer. Cancer Research, 48, 3282-3287.

[6] Zeng, J., Tang, Y., Wu, P., Fang, X., Wang, W., Fan, Y., Li, X. and Zhao, S. (2019) Alcohol Consumption, Tobacco Smoking, Betel Quid Chewing and Oral Health Associations with Hypopharyngeal Cancer among Men in Central South China: A Case-Control Study. Cancer Management and Research, 11, 6353-6364. https://doi.org/10.2147/CMAR.S203439

[7] Tanon-Anoh, M.J., Badou, K.E., Yoda, M., Kouassi, N., Koffi, A., ETTE, A. and Kouassi, B. (2011) Epidémiologie et clinique des cancers du pharynx à Abidjan. Médecine d'Afrique Noire, 58, 248-252.

[8] Lapotre-Ledou, B., Guizard, A.V., Bara, S., et al. (2015) Cancer de l'hypopharynx: Epidémiologie et prise en charge dans le nord-ouest de la France.

https://studylibfr.com/

[9] Ndiaye, I., Ndamage, T.D., Adama, T., Diouf, R. and Diop, E.M. (1997) Profil des cancers de l'hypopharynx au Sénégal. Annales d Otolaryngologie et de Chirurgie Cervico-Faciale, 114, 86-89.

[10] Helliwell, T.R. (2003) Evidence Based Pathology: Squamous Carcinoma of the Hypopharynx. Journal of Clinical Pathology, 56, 81-85. https://doi.org/10.1136/jcp.56.2.81

[11] Michaels, L. (1987) Squamous Carcinoma of the Hypopharynx. In: Ear Nose and Throat Histopathology. Springer-Verlag, London, 459-463. https://doi.org/10.1007/978-1-4471-3332-2

[12] Roboson, A. (2002) Evidence-Based Management of Hypopharyngeal Cancer. Meeting Report. Clinical Otolaryngology, 27, 413-420. https://doi.org/10.1046/j.1365-2273.2002.00570.x

[13] Doll, R., Peto, R., Boreham, J. and Sutherland, I. (2004) Mortality in Relation to Smoking: 50 Years' Observations on Male British Doctors. BMJ, 328, 1519-1533. https://doi.org/10.1136/bmj.38142.554479.AE 